\title{
An indirect comparison of infliximab versus adalimumab or golimumab for active ulcerative colitis
}

\author{
Paweł Kawalec ${ }^{1}$, Andrzej Pilc ${ }^{2}$
}

${ }^{1}$ Drug Management Department, Institute of Public Health, Faculty of Health Sciences, Jagiellonian University Medical College, Krakow, Poland ${ }^{2}$ Institute of Pharmacology, Polish Academy of Sciences, Krakow, Poland

Submitted: 13 May 2015

Accepted: 19 October 2015

Arch Med Sci 2016; 12, 5: 1097-1109

DOI: 10.5114 /aoms.2016.58682

Copyright $\odot 2016$ Termedia \& Banach

\section{Abstract}

Introduction: The aim of the study was to compare adalimumab or golimumab with infliximab in patients with moderately-to-severely active ulcerative colitis (UC).

Material and methods: This paper was prepared according to the PRISMA guidelines. The systematic literature search was performed in PubMed, Embase, and Cochrane Library. No direct head-to-head comparisons for infliximab vs. adalimumab or golimumab were available so an indirect comparison according to the Bucher method was performed after a homogeneity evaluation of the included studies.

Results: Six RCTs were included in the systematic review. An indirect comparison was performed, which revealed that infliximab was more effective in inducing clinical response compared with both doses of adalimumab (160/80 mg or $80 / 40 \mathrm{mg} ; p<0.05)$, and, in clinical remission, infliximab was more effective than adalimumab (only for a dosage regime of $80 / 40 \mathrm{mg}$; $p<0.05)$. No statistically significant differences in clinical response and clinical remission were observed between infliximab and golimumab in the induction phase. A significant $(p<0.05)$ advantage only of infliximab compared with adalimumab at doses of $80 / 40 \mathrm{mg}$ and $80 / 160 \mathrm{mg}$ was seen in terms of clinical response in the maintenance phase (up to 52-54 weeks). The indirect comparison revealed that serious adverse events were significantly more frequent among patients treated with a maintenance dose of $100 \mathrm{mg}$ of golimumab compared with those treated with infliximab $(p<0.05)$.

Conclusions: No significant differences in efficacy in the maintenance phase between infliximab and golimumab or adalimumab were revealed. Infliximab proved to be more effective than adalimumab but of similar efficacy to that of golimumab in the induction phase.

Key words: infliximab, adalimumab, golimumab, ulcerative colitis, biological therapy, systematic review, indirect comparison.

\section{Introduction}

Ulcerative colitis (UC) is a type of inflammatory bowel disease that affects the mucosa of the colon [1-3], usually diagnosed at the age of 20 to 30 years, and is always a chronic life-long condition [4]. The condition is more and more common worldwide, especially in highly developed societies, and its prevalence varies by geographic region, ranging from 4.9 to 505 per 100000 in Europe, 4.9 to 168.3 per 100000 in Asia and the Mid-

\author{
Corresponding author: \\ Paweł Kawalec \\ Drug Management \\ Department \\ Institute of Public Health \\ Faculty of Health Sciences \\ Jagiellonian University \\ Medical College \\ 20 Grzegorzecka St \\ 31-531 Krakow, Poland \\ Phone: +48 607345792 \\ E-mail: \\ pawel.kawalec@uj.edu.pl
}


dle East, and 37.5 to 248.6 per 100000 in North America [3, 4]. The fact that the highest incidence and prevalence of UC are in the populations of Europe and North America is considered to be linked to genetic factors, environment, and lifestyle, particularly to a diet high in fat and sugar, alcohol, medication use, stress, and high socioeconomic status [1, 3, 5-12]. The goal of therapy in UC is to induce and maintain remission, improve quality of life, and prevent colectomy [13-15].

Conventional therapy of ulcerative colitis includes corticosteroids and immunosuppressives (e.g. azathioprine, methotrexate); in the case of lack of such therapy, biologic treatment should be introduced; moreover, in some patients there is no clinical improvement after pharmacotherapy, so surgery (colectomy) has to be performed. Immunosuppressives have limited efficacy due to inadequate control of the disease, especially in patients with more advanced disease, and this is often associated with the risk of intolerance or resistance to concurrent treatment $[3,13]$. Because of that and the increasing prevalence of UC [5], identification of an alternative and more effective treatment is crucial to increase the number of available therapeutic options and to improve clinical outcomes [3]. In a number of patients a biologic therapy is used with tumor necrosis factor (TNF) antagonists; among them infliximab is the most commonly used; other potentially useful monoclonal antibodies for UC include adalimumab and golimumab [3]. Infliximab, adalimumab and golimumab have been approved for the treatment of UC by the U.S. Food and Drug Administration (FDA) and the European Medicines Agency (EMA) [16, 17]; infliximab was the first biologic agent authorized in the therapy of UC; currently it is very often used for this indication, usually in the first stage of biologic therapy; adalimumab and golimumab are newer alternatives; the most recent, golimum$a b$, was introduced in the European Union for this indication in 2013. Infliximab, adalimumab, and golimumab are antagonists of the TNF. All of them bind soluble and transmembrane TNF, neutralizing TNF activity and inhibiting binding to TNF receptors. In addition, infliximab and adalimumab are responsible for the induction of activated $T$ cells and macrophage apoptosis; adalimumab also lyses TNF-expressing cells by complement-dependent cytotoxicity [3, 18-20].

Therefore, the aim of this systematic review was to evaluate the clinical efficacy and safety of newer biologic drugs (adalimumab and golimum$a b)$ in comparison with infliximab in patients with moderately-to-severely active UC. Owing to the lack of evidence from head-to-head studies comparing different biologics, an indirect method may provide useful information about their relative efficacy. Therefore, we applied a valid, adjusted indirect comparison assessment according to the Bucher method, being one of the most suitable approaches for indirect treatment comparisons of randomized controlled trials (RCTs). This method is based on the assumption that indirect evidence is consistent with the direct comparison. It is also based on a meta-analysis but compares the value of treatment effects in RCTs of the interventions in comparison with placebo or a control group. Supposing that treatments $A$ and $C$ are compared in one RCT, and treatments $B$ and $C$ are compared in another RCT, then the indirect comparison of $A$ and $B$ is adjusted according to the results of their direct comparisons with a common intervention (comparator) - C [21, 22]. In our previous study, we analyzed the efficacy and safety of biologic drugs in comparison with placebo for the treatment of active UC [3]. Currently, we would like to perform further research to investigate the difference between biologics with the best method available - an indirect comparison.

\section{Material and methods}

\section{Search strategy and study selection}

As described in detail previously [3] the systematic review was conducted and reported according to the methods and recommendations from the Preferred Reporting Items for Systematic Reviews and Meta-Analysis (PRISMA) Statement [23] and the Cochrane Handbook [24]. The systematic literature review was conducted using the main electronic databases, Medline via PubMed, Embase, and the Cochrane Central Register of Controlled Trials, until 27 November 2014. The key words ulcerative colitis (population) and infliximab or adalimumab or golimumab (intervention) were used to find relevant citations. Only English, French, and German publications were included. The search strategy was presented with the QUOROM diagram (Figure 1). Two reviewers independently conducted the search and selection of studies on the basis of the previously established inclusion criteria. The decision for inclusion was made by consensus to reach the final decision. The Clinical Trials Register (www.clinicaltrials.gov) was searched for unpublished or ongoing trials.

Compared datasets included data only from randomized, double-blind, placebo-controlled, and parallel trials of phase II/III studies. Results from nonrandomized or uncontrolled open-label studies were not incorporated into the dataset [25]. The population of interest comprised adults with moderately-to-severely active UC (confirmed by biopsy and defined as a Mayo score ranging from 6 to 12 points with an endoscopy subscore of at least 2) despite concurrent treatment with stable 


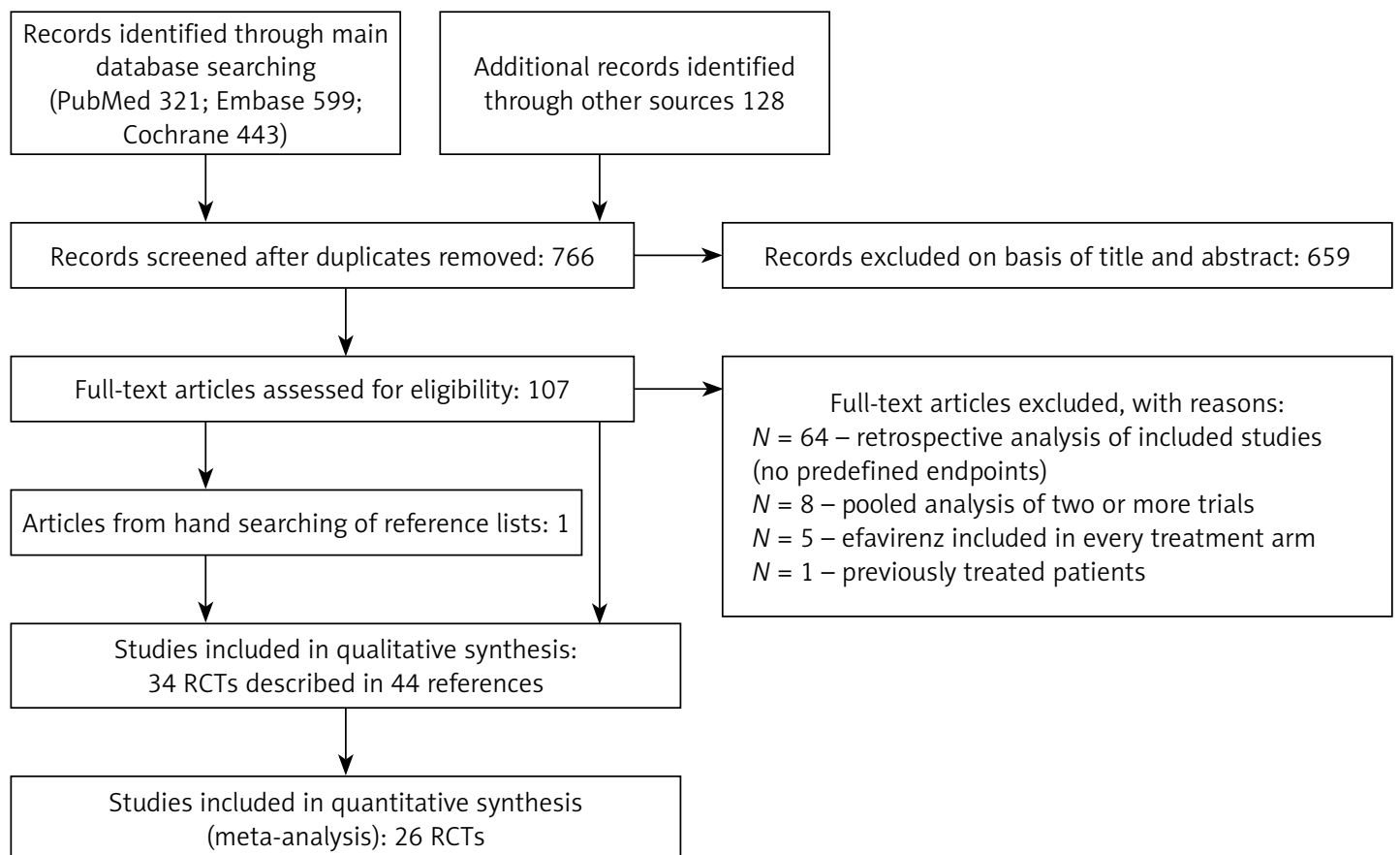

Figure 1. Study flow diagram showing the results of the search and process of screening and selecting studies for inclusion in the indirect comparison

doses of oral corticosteroids or immunomodulators (such as azathioprine or 6-mercaptopurine), or both. Patients concurrently treated with oral corticosteroids or immunomodulators were receiving a stable dose prior to baseline. Concurrent therapy was not required for patients who failed to respond to or could not tolerate previous corticosteroid or immunomodulator treatment, as assessed by the investigator. Patients who received infliximab, adalimumab, golimumab, or any other anti-TNF therapy in the past were not eligible. The key exclusion criteria included a history of colectomy or planned bowel surgery, ongoing infections (in particular confirmed tuberculosis), or use of any investigational agent within 30 days or five half-lives prior to baseline.

Results from the included studies were analyzed separately for the induction phase (data extracted at 6 to 8 weeks) and maintenance phase (data extracted at 52 to 54 weeks of treatment).

Studies with efficacy or safety assessments made after 54 weeks of treatment were excluded from the analysis [26, 27]. Furthermore, studies with different definitions of clinical response and clinical remission were not included [25, 27-30]. Conference abstracts were excluded owing to the lack of appropriate data and detailed information regarding methodology and obtained results.

\section{Data extraction and quality assessment}

All data were extracted by P.K. and then checked by A.P. The extracted data contained patients' characteristics, study design, drug dos- es, duration of treatment, outcome measures/ definition of endpoints, proportion of participants achieving particular predefined endpoints, and the number of any adverse events and serious adverse events during treatment. Data included in the indirect comparison were extracted from trial groups that adhered to the dose regimens approved by the EMA. Trials with unapproved dose regimens were excluded from the analysis. The exception was an adalimumab dose of $80 / 40 \mathrm{mg}$, which was not consistent with the dose regimens approved by the EMA, but was also included in the data analysis. This was because, according to the reference publication [31], the study protocol had been expanded to include two dose regimens of adalimumab: the first adhered to that approved by the EMA, and the second was ADA80/40, namely, $80 \mathrm{mg}$ at week 0 and $40 \mathrm{mg}$ at weeks 2, 4 and 6 . The same doses of adalimumab were also used in another clinical trial [32]. In cases of multi-arm placebo-controlled trials using infliximab and golimumab, relevant data were extracted only for the arms with an approved regimen and the placebo arm. Different doses of the same biologic drug were regarded and presented as separate interventions. The methodological quality of eligible RCTs was assessed using the Jadad scale [33].

\section{Treatment regimen for biologic drugs}

According to the registration status in the European Union, the approved infliximab regimen for the treatment of active UC in adult patients is $5 \mathrm{mg} / \mathrm{kg}$ of body mass administered at weeks 0,2 , 
and 6 , followed by $5 \mathrm{mg} / \mathrm{kg}$ every 8 weeks [34]. The approved adalimumab regimen is $160 \mathrm{mg}$ at week 0 , followed by $80 \mathrm{mg}$ at week 2 , and $40 \mathrm{mg}$ every 2 weeks thereafter (patients who experience a decrease in their response may benefit from an increase in dosing frequency to $40 \mathrm{mg}$ of adalimumab every week) [35]. The approved golimumab regimen is $200 \mathrm{mg}$ and $100 \mathrm{mg}$ at weeks 0 and 2, respectively, followed by $50 \mathrm{mg}$ (or $100 \mathrm{mg}$ for patients weighing over $80 \mathrm{~kg}$ ) every 4 weeks [36].

\section{Outcomes}

The primary efficacy outcomes were the percentage of patients achieving clinical remission and clinical response after both the induction phase (6-8 weeks) and maintenance phase of drug administration (52-54 weeks). Clinical remission was defined as a Mayo score of 2 or fewer points, with no individual subscore greater than 1 point, while clinical response was defined as a decrease from the baseline value (observed in the preceding induction phase) in the Mayo score by $30 \%$ or more and 3 or more points, with either a decrease in the rectal bleeding subscore of 1 or more or a rectal bleeding subscore of 0 or 1 point. The safety analysis of the treatment with TNF- $\alpha$ inhibitors was based on the incidence of any adverse events and serious adverse events occurring during maintenance treatment (up to 52-54 weeks).

\section{Indirect comparison}

Using the extracted data we prepared an adjusted indirect comparison using random- or fixed-effects models depending on the heterogeneity of the analyzed population. The heterogeneity test based on the Cochrane Q statistic estimation was used; when the compared populations were homogeneous (Cochane $\mathrm{Q}$ test $p>0.1$ ), the inverse variance fixed-effects model was used in a meta-analysis, and when the compared populations were heterogeneous (Cochrane $\mathrm{Q}$ test $p \leq 0.1$ ), the DerSimonian and Laird random-effects model was applied. We obtained comparative relative risks with $95 \%$ confidence intervals for prespecified outcomes and adverse events.

\section{Results}

\section{Identified studies}

The systematic review revealed six RCT studies that met our inclusion criteria. The results of these six clinical trials were presented in nine publications: one of these RCTs used infliximab vs. placebo [37, 38]; four used adalimumab vs. placebo [31, $32,39-41]$; and two used golimumab vs. placebo $[42,43]$ in the treatment of UC. Table I summa- rizes the characteristics of trials included in the adjusted indirect comparison.

All biologic drugs in the included trials were compared with placebo, which was a common comparator in the Bucher method. A heterogeneity analysis of the included studies was also performed and revealed that they did not differ in terms of patients' characteristics or the definition of selected endpoints such as clinical response and clinical remission. The studies were homogeneous enough to be used in the indirect comparison (Table II).

The methodological quality of the included RCTs was evaluated as high (one trial [31] scored four points and the other five trials [32, 37-43] scored three points). All eligible trials were randomized and double-blind. They also provided data on the number of patient withdrawals.

\section{Efficacy of biologic therapy (clinical response and clinical remission)}

Indirect comparisons between different biologic treatments showed that during the induction phase of treatment, infliximab $[37,38]$ was more effective than adalimumab [31, 32, 39-41] given at both doses, namely, 160/80 mg and 80/40 mg (Table III). However, for the maintenance phase of treatment, no significant differences between infliximab [37, 38] and adalimumab [31, 32, 39-41] were revealed (Figure 2; Table III). Furthermore, we did not observe any significant differences in clinical response between infliximab $[37,38]$ and golimumab $[42,43]$ in either the induction or the maintenance phase of drug administration (Figure 2; Table III).

An indirect comparison analysis demonstrated that clinical remission during the induction phase was significantly more often observed among patients treated with infliximab $[37,38]$ than among those treated with adalimumab [31, 32, 39-41] given at a dose of $80 / 40 \mathrm{mg}$ (Figure 2, Table III). Differences between infliximab $[37,38]$ and adalimumab [31, 32, 39-41] at a dose of $160 / 80 \mathrm{mg}$ or golimumab $[42,43]$ were not revealed during the induction phase of treatment (Table III). Similarly, the frequency of clinical remission among patients treated with infliximab $[37,38]$ or adalimumab [31, 32, 39-41] and those treated with infliximab $[37,38]$ or golimumab $[42,43]$ at the end of the maintenance phase of treatment did not differ significantly (Figure 2; Table III).

To summarize, our indirect comparison showed that in the maintenance phase of drug administration, all tested biologic drugs presented similar efficacy measured by clinical response and clinical remission rates. Moreover, the study revealed no significant difference between infliximab and golimumab in the induction phase of drug administration. 
Table I. Studies included in the indirect comparison of infliximab vs adalimumab or golimumab

\begin{tabular}{|c|c|c|c|}
\hline $\begin{array}{l}\text { Trial (first author, publication year) } \\
\text { [reference] }\end{array}$ & $\begin{array}{l}\text { Treatment arms (only } \\
\text { comparisons relevant to this } \\
\text { meta-analysis are listed) }\end{array}$ & $\begin{array}{l}\text { Number of } \\
\text { patients }\end{array}$ & $\begin{array}{l}\text { Timing of outcome } \\
\text { assessment [week] }\end{array}$ \\
\hline \multirow{2}{*}{$\begin{array}{l}\text { ACT 1, ACT } 2 \text { (Rutgeerts, } 2005 \text { [37]; } \\
\text { Sandborn, } 2009 \text { [38]) }\end{array}$} & IFX $5 \mathrm{mg}$ & $242 / 121$ & 8 and 54 \\
\hline & Placebo & $244 / 123$ & \\
\hline \multirow[t]{3}{*}{ Suzuki, 2014 [32] } & ADA $160 / 80 \mathrm{mg}$ & 90 & 8 and 52 \\
\hline & ADA $80 / 40 \mathrm{mg}$ & 87 & \\
\hline & Placebo & 96 & \\
\hline \multirow{2}{*}{$\begin{array}{l}\text { ULTRA } 2 \text { (Sandborn, } 2012 \text { [39]; } \\
\text { Sandborn, } 2013 \text { [40]; } \\
\text { Feagan, } 2014 \text { [41]) } \\
\end{array}$} & ADA $160 / 80 \mathrm{mg}$ & 248 & 8 and 52 \\
\hline & Placebo & 246 & \\
\hline \multirow{3}{*}{$\begin{array}{l}\text { ULTRA } 1 \text { (Reinisch, } 2011 \text { [31]; } \\
\text { Feagan, } 2014 \text { [41]) }\end{array}$} & ADA $160 / 80 \mathrm{mg}$ & 130 & 8 \\
\hline & ADA $80 / 40 \mathrm{mg}$ & 130 & \\
\hline & Placebo & 130 & \\
\hline \multirow[t]{2}{*}{ PURSUIT-SC (Sandborn, 2014 [42]) } & GOL 200/100 mg & 253 & 6 \\
\hline & Placebo & 251 & \\
\hline \multirow[t]{3}{*}{ PURSUIT-M (Sandborn, 2014 [43]) } & GOL $50 \mathrm{mg}$ & 154 & 52 \\
\hline & GOL $100 \mathrm{mg}$ & 154 & \\
\hline & Placebo & 156 & \\
\hline
\end{tabular}

IFX - infliximab, ADA - adalimumab, GOL - golimumab.

Infliximab seems to have better efficacy than adalimumab (160/80/40 $\mathrm{mg})$ in the induction phase of drug administration only in the case of clinical response, and we did not observe any significant differences in clinical remission between these two drugs.

In addition, due to the fact that the clinical remission of the disease (defined as a total Mayo score of 2 points or lower, with no individual subscore exceeding 1 point) is contained in the definition of clinical response (defined as a decrease from baseline in the total Mayo score of at least 3 points and at least $30 \%$, with an accompanying decrease in the subscore for rectal bleeding of at least 1 point or an absolute subscore for rectal bleeding of 0 or 1 ), we decided to carry out an indirect comparison of the analyzed substances in the field of clinical response without clinical remission.

The indirect comparison showed no significant difference in clinical response between infliximab $[37,38]$ or adalimumab [31, 32, 39-41] and infliximab [37, 38] or golimumab [42] during the induction phase (6-8 weeks) (Figure 3; Table IV). Also, an indirect comparison of clinical response in the maintenance phase (up to 52-54 weeks) between infliximab [37, 38] or adalimumab [31, 32, 39-41] and infliximab [37, 38] or golimumab [42] showed no significant differences, except for a significant advantage of infliximab at a dose of $5 \mathrm{mg}[37,38]$ over adalimumab at doses of $80 \mathrm{mg} / 40 \mathrm{mg}[31,32]$ and 80/160 mg [31, 32, 39-41] (Figure 3; Table IV).

\section{Safety of biologic therapy}

We analyzed the incidence of any adverse events and serious adverse events occurring only during maintenance treatment (up to 52-54 weeks) for all biologics because in publications describing studies of infliximab $[37,38]$, no data on adverse events in the induction phase of treatment were available. Moreover, the safety profile assessment in the maintenance phase, that is, after a longer period of drug administration, is more reliable and makes it possible to identify any, including rare or unexpected, adverse events of therapy and provides more accurate safety data than in a short follow-up.

Data used in the case of the safety profile assessment of adalimumab have been presented in three publications [32, 39-41]; however, because of insufficient data for indirect comparison, some additional information was provided by the ClinicalTrials.gov database [44].

The indirect comparison showed that there is no difference in the frequency of overall adverse events among patients treated with infliximab $[37,38]$ in comparison with those treated with adalimumab [32, 39-41] or golimumab [43] (Figure 4 ; Table V). In the case of patients treated with a maintenance golimumab dose of $100 \mathrm{mg}$ [43], 
Paweł Kawalec, Andrzej Pilc

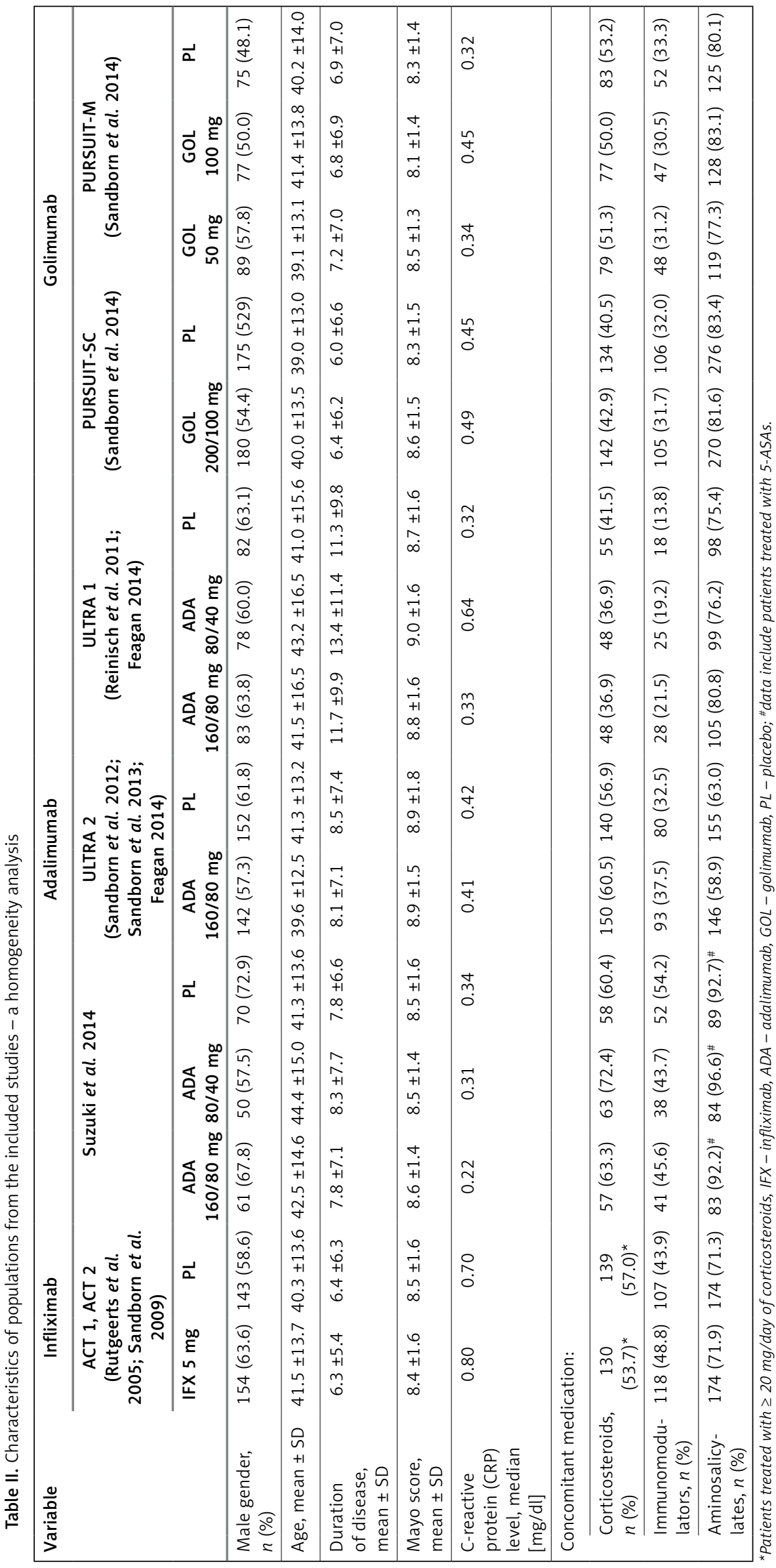


Table III. Results of an adjusted indirect comparison between the efficacy of infliximab and adalimumab or infliximab and golimumab

\begin{tabular}{|c|c|c|c|c|}
\hline \multirow[t]{2}{*}{ Variable } & \multicolumn{2}{|c|}{ 6-8 weeks } & \multicolumn{2}{|c|}{ 52-54 weeks } \\
\hline & $\begin{array}{l}\text { Clinical response } \\
(\operatorname{RR}(95 \% \mathrm{Cl}))\end{array}$ & $\begin{array}{l}\text { Clinical remission } \\
\quad(\operatorname{RR}(95 \% \mathrm{CI}))\end{array}$ & $\begin{array}{l}\text { Clinical response } \\
(\operatorname{RR}(95 \% \mathrm{CI}))\end{array}$ & $\begin{array}{l}\text { Clinical remission } \\
\quad(\mathrm{RR}(95 \% \mathrm{CI}))\end{array}$ \\
\hline \multicolumn{5}{|c|}{ Infliximab 5 mg vs. adalimumab 160/80 mg } \\
\hline $\begin{array}{l}\text { Infliximab [37], [38] vs. } \\
\text { adalimumab [31], [32], } \\
\text { [39-41] }\end{array}$ & $\begin{array}{c}1.47(1.15-1.87) \\
p=0.0022\end{array}$ & $\begin{array}{c}2.35(0.96-5.81) \\
p>0.05\end{array}$ & $\begin{array}{c}1.39(0.82-2.33) \\
\quad p>0.05\end{array}$ & $\begin{array}{c}1.03(0.52-2.04) \\
\quad p>0.05\end{array}$ \\
\hline \multicolumn{5}{|c|}{ Infliximab 5 mg vs. adalimumab $80 / 40$ mg } \\
\hline $\begin{array}{l}\text { Infliximab [37], [38] vs. } \\
\text { adalimumab [31], [32] }\end{array}$ & $\begin{array}{c}1.71(1.28-2.28) \\
p=0.0002\end{array}$ & $\begin{array}{c}3.27(1.25-8.57) \\
p=0.0158\end{array}$ & NA & NA \\
\hline \multicolumn{5}{|c|}{ Infliximab 5 mg vs. adalimumab 40 mg } \\
\hline $\begin{array}{l}\text { Infliximab [37], [38] vs. } \\
\text { adalimumab [31], [32], } \\
\text { [39-41] }\end{array}$ & NA & NA & $\begin{array}{c}1.36(0.83-2.22) \\
p>0.05\end{array}$ & $\begin{array}{c}0.91(0.49-1.69) \\
p>0.05\end{array}$ \\
\hline \multicolumn{5}{|c|}{ Infliximab 5 mg vs. golimumab 200/100 mg } \\
\hline $\begin{array}{l}\text { Infliximab [37], [38] vs. } \\
\text { golimumab [42] }\end{array}$ & $\begin{array}{c}1.18(0.88-1.59) \\
\quad p>0.05\end{array}$ & $\begin{array}{c}1.34(0.51-3.52) \\
p>0.05\end{array}$ & NA & NA \\
\hline \multicolumn{5}{|c|}{ Infliximab 5 mg vs. golimumab 100 mg } \\
\hline $\begin{array}{l}\text { Infliximab [37], [38] vs. } \\
\text { golimumab [43] }\end{array}$ & NA & NA & $\begin{array}{c}1.44(0.87-2.36) \\
p>0.05\end{array}$ & $\begin{array}{c}1.23(0.64-2.33) \\
p>0.05\end{array}$ \\
\hline \multicolumn{5}{|c|}{ Infliximab 5 mg vs. golimumab 50 mg } \\
\hline $\begin{array}{l}\text { Infliximab [37], [38] vs. } \\
\text { golimumab [43] }\end{array}$ & NA & NA & $\begin{array}{c}1.52(0.92-2.51) \\
p>0.05\end{array}$ & $\begin{array}{c}1.47(0.76-2.84) \\
p>0.05\end{array}$ \\
\hline
\end{tabular}

\section{Forest (meta-analysis)}

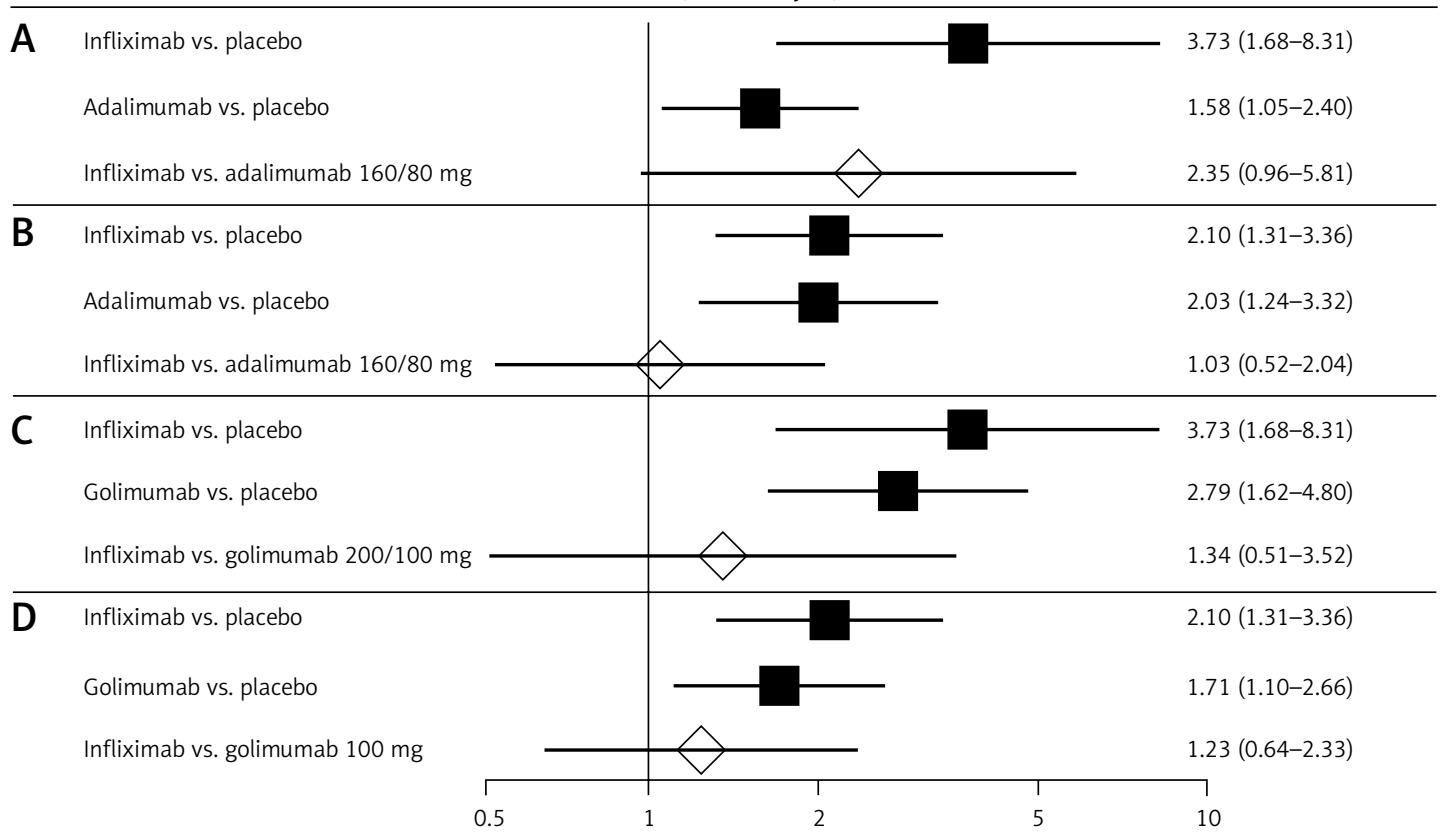

Figure 2. Forest plot of direct estimates for: A - infliximab (5 mg) vs. placebo and adalimumab $(160 / 80 \mathrm{mg})$ vs. placebo, and indirect comparison between the treatments in the case of clinical remission after 6-8 weeks of drug administration; B - infliximab $(5 \mathrm{mg})$ vs. placebo and adalimumab $(160 / 80 \mathrm{mg})$ vs. placebo, and indirect comparison between treatments in the case of clinical remission after 52-54 weeks of drug administration; C - infliximab (5 mg) vs. placebo and golimumab (200/100 mg) vs. placebo, and indirect comparison between treatments in the case of clinical remission after 6-8 weeks of drug administration; D - infliximab (5 mg) vs. placebo and golimumab $(100 \mathrm{mg})$ vs. placebo, and indirect comparison between treatments in the case of clinical remission after 52-54 weeks of drug administration 
Forest (meta-analysis)

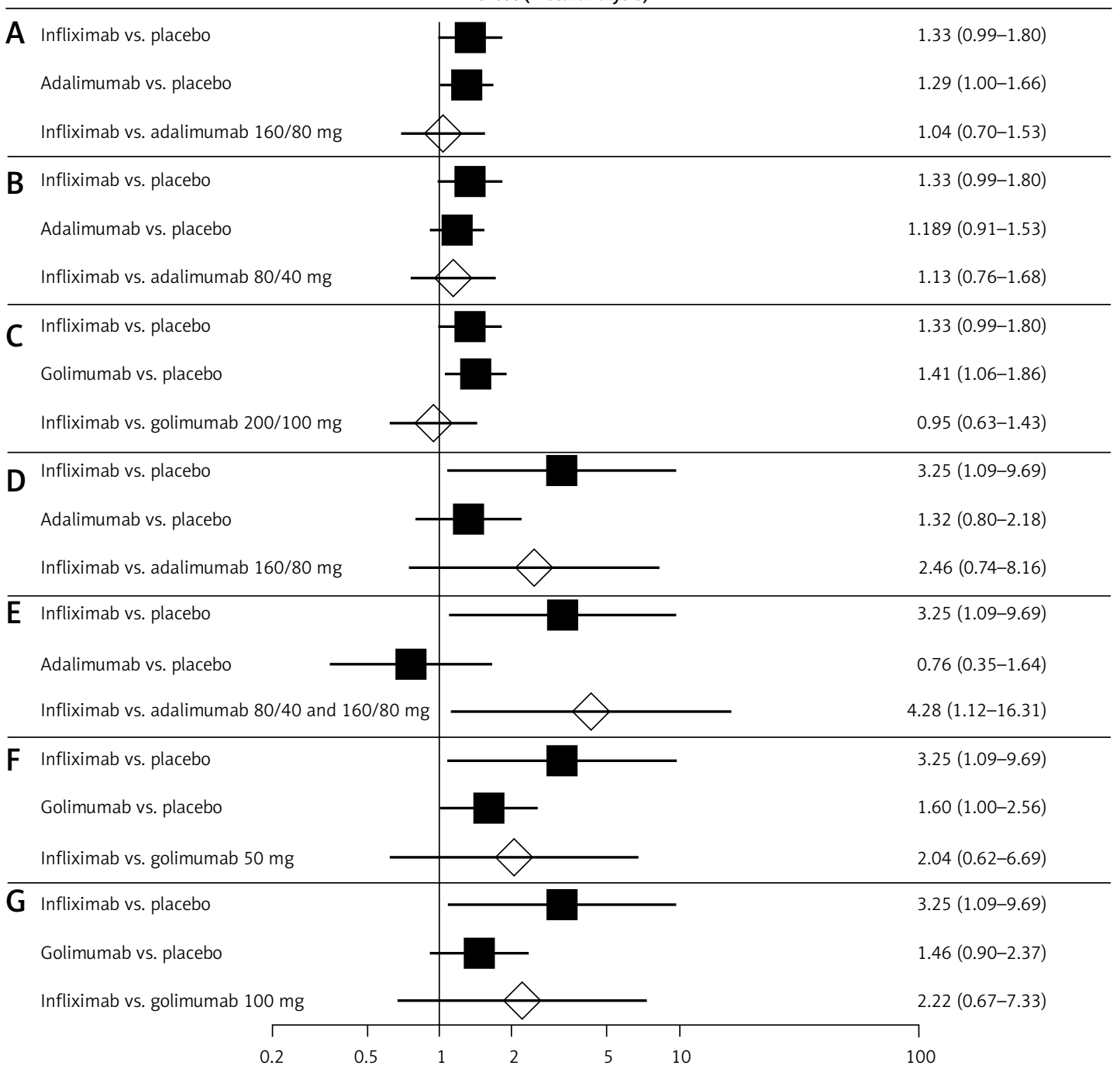

Figure 3. Forest plot of direct estimates for: A - infliximab ( $5 \mathrm{mg})$ vs. placebo and adalimumab (160/80 mg) vs. placebo, and indirect comparison between the treatments in the case of clinical response after 6-8 weeks of drug administration; B - infliximab (5 mg) vs. placebo and adalimumab (80/40 mg) vs.placebo, and indirect comparison between the treatments in the case of clinical response after 6-8 weeks of drug administration; $\mathbf{C}-$ infliximab (5 mg) vs. placebo and golimumab (200/100 mg) vs. placebo, and indirect comparison between treatments in the case of clinical response after 6-8 weeks of drug administration; D - infliximab (5 mg) vs. placebo and adalimumab (160/80 mg) vs. placebo, and indirect comparison between treatments in the case of clinical response after 52-54 weeks of drug administration; E - infliximab (5 mg) vs. placebo and adalimumab (80/40) and (160/80) mg vs. placebo, and indirect comparison between treatments in the case of clinical response after 52-54 weeks of drug administration; F - infliximab (5 mg) vs. placebo and golimumab (50 mg) vs. placebo, and indirect comparison between treatments in the case of clinical response after 52-54 weeks of drug administration; G - infliximab $(5 \mathrm{mg})$ vs. placebo and golimumab $(100 \mathrm{mg})$ vs. placebo, and indirect comparison between treatments in the case of clinical response after 52-54 weeks of drug administration

serious adverse events were significantly more frequent than in the case of patients treated with infliximab [37, 38] (Figure 4; Table V).

\section{Discussion}

Ulcerative colitis is a relapsing disease that is difficult to treat, and a high percentage of patients are refractory to traditional medical management $[45,46]$. As described in detail previously [3] the goal of therapy in patients with UC is the induction and maintenance of a clinical response and remis- sion to prevent the risk of colectomy and possible complications related to this procedure, such as pouchitis, incontinence, or pelvic sepsis [47-49].

Anti-TNF- $\alpha$ monoclonal antibodies, such as golimumab, adalimumab, and infliximab, bind TNF, neutralizing its activity, and inhibit binding to TNF receptors [18-20]. As described previously [3] the efficacy of infliximab and adalimumab in the therapy of patients with moderate-to-severe UC was proved in individual studies [29-31, 37-39, 44] as well as in the meta-analyses conducted by Law- 
Table IV. Results of an adjusted indirect comparison between the efficacy of infliximab and adalimumab or infliximab and golimumab in terms of clinical response

\begin{tabular}{|c|c|c|}
\hline \multirow[t]{2}{*}{ Variable } & $6-8$ weeks & 52-54 weeks \\
\hline & $\begin{array}{l}\text { Clinical response } \\
(\operatorname{RR}(95 \% \mathrm{Cl}))\end{array}$ & $\begin{array}{l}\text { Clinical response } \\
(\mathrm{RR}(95 \% \mathrm{Cl}))\end{array}$ \\
\hline \multicolumn{3}{|c|}{ Infliximab 5 mg vs. adalimumab 160/80 mg } \\
\hline $\begin{array}{l}\text { Infliximab [37], [38] vs. } \\
\text { adalimumab [31], [32], [39-41] }\end{array}$ & $\begin{array}{c}1.04(0.70-1.53) \\
\quad p>0.05\end{array}$ & $\begin{array}{l}2.46(0.74-8.16) \\
\quad p>0.05\end{array}$ \\
\hline \multicolumn{3}{|c|}{ Infliximab 5 mg vs. adalimumab $80 / 40$ mg } \\
\hline $\begin{array}{l}\text { Infliximab [37], [38] vs. } \\
\text { adalimumab [31], [32] }\end{array}$ & $\begin{array}{c}1.13(0.76-1.68) \\
p>0.05\end{array}$ & NA \\
\hline \multicolumn{3}{|c|}{ Infliximab 5 mg vs. adalimumab $80 / 40 \mathrm{mg}$ and $80 / 160 \mathrm{mg}$} \\
\hline $\begin{array}{l}\text { Infliximab [37], [38] vs. } \\
\text { adalimumab [31], [32], [39-41] }\end{array}$ & NA & $\begin{array}{c}4.28(1.12-16.31) \\
p=0.0331\end{array}$ \\
\hline \multicolumn{3}{|c|}{ Infliximab 5 mg vs. golimumab 200/100 mg } \\
\hline $\begin{array}{l}\text { Infliximab [37], [38] vs. } \\
\text { golimumab [42] }\end{array}$ & $\begin{array}{c}0.95(0.63-1.43) \\
\quad p>0.05\end{array}$ & NA \\
\hline \multicolumn{3}{|c|}{ Infliximab 5 mg vs. golimumab 100 mg } \\
\hline $\begin{array}{l}\text { Infliximab [37], [38] vs. } \\
\text { golimumab [43] }\end{array}$ & NA & $\begin{array}{c}2.22(0.67-7.33) \\
\quad p>0.05\end{array}$ \\
\hline \multicolumn{3}{|l|}{ Infliximab 5 mg vs. golimumab 50 mg } \\
\hline $\begin{array}{l}\text { Infliximab [37], [38] vs. } \\
\text { golimumab [43] }\end{array}$ & NA & $\begin{array}{c}2.04(0.62-6.69) \\
p>0.05\end{array}$ \\
\hline
\end{tabular}

son et al. [50] and Ford et al. [51], and which also demonstrated the superiority of infliximab over placebo in patients with moderate-to-severe UC.

This systematic review and indirect comparison has both limitations and strengths. One of the limitations was the lack of head-to-head studies comparing different biologics, so traditional methods could not be applied for the comparison. Therefore, we used the Bucher method to compare the efficacy of biologics. The Bucher method is an indirect comparison of competing interventions adjusted according to the results of their direct comparison with a common intervention or placebo. The method can protect against some biases, and the advantage of RCTs can be at least partly preserved when an indirect comparison is used [21], although it is usually a worse and less credible analytic tool than a head-to-head comparison in an RCT. It should be underlined that the results of indirect comparisons are characterized by limited reliability because such a comparison is always burdened with a certain methodical error that is impossible to omit in a comparison of two different clinical trials using a common comparator [22]. An indirect analysis, although less reliable than a direct comparison, allows one to draw conclusions about the clinical effectiveness of the analyzed therapeutic options, especially because if you manage to conduct a meta-analysis from the most homogeneous data of the identified clinical studies, it increases the number of patients taken into account and, therefore, influences the reliabil- ity of the results. The results of the indirect comparison of infliximab vs. adalimumab, and infliximab vs. golimumab, by the Bucher method had provided the most reliable data until the appearance of head-to-head studies. A direct comparison trial between the drugs will be the best way to compare the clinical effectiveness and safety of the biologic therapy, but until such studies have been performed the indirect comparison is the only available method to compare the drugs; clinical trials directly comparing the drugs are urgently needed.

As part of this study, a possibility to conduct a mixed treatment comparison (MTC) instead of an indirect comparison was also considered. The MTC is a statistical method that allows one to simultaneously compare numerous therapeutic options, taking into account the results of direct and indirect comparisons. It is used in the case of numerous alternative interventions; however, direct comparisons are only made between some of the interventions, and when the results of the indirect comparison do not allow one to reach unequivocal conclusions. Nevertheless, the use of the MTC is risky, because different studies included in a meta-analysis or systematic review are often clinically and methodically nonhomogeneous, so the results have very limited reliability [52]. Ultimately, we decided to use a more reliable method, namely, the indirect comparison according to Bucher. Moreover, an MTC (also known as network meta-analysis) comparing the efficacy 


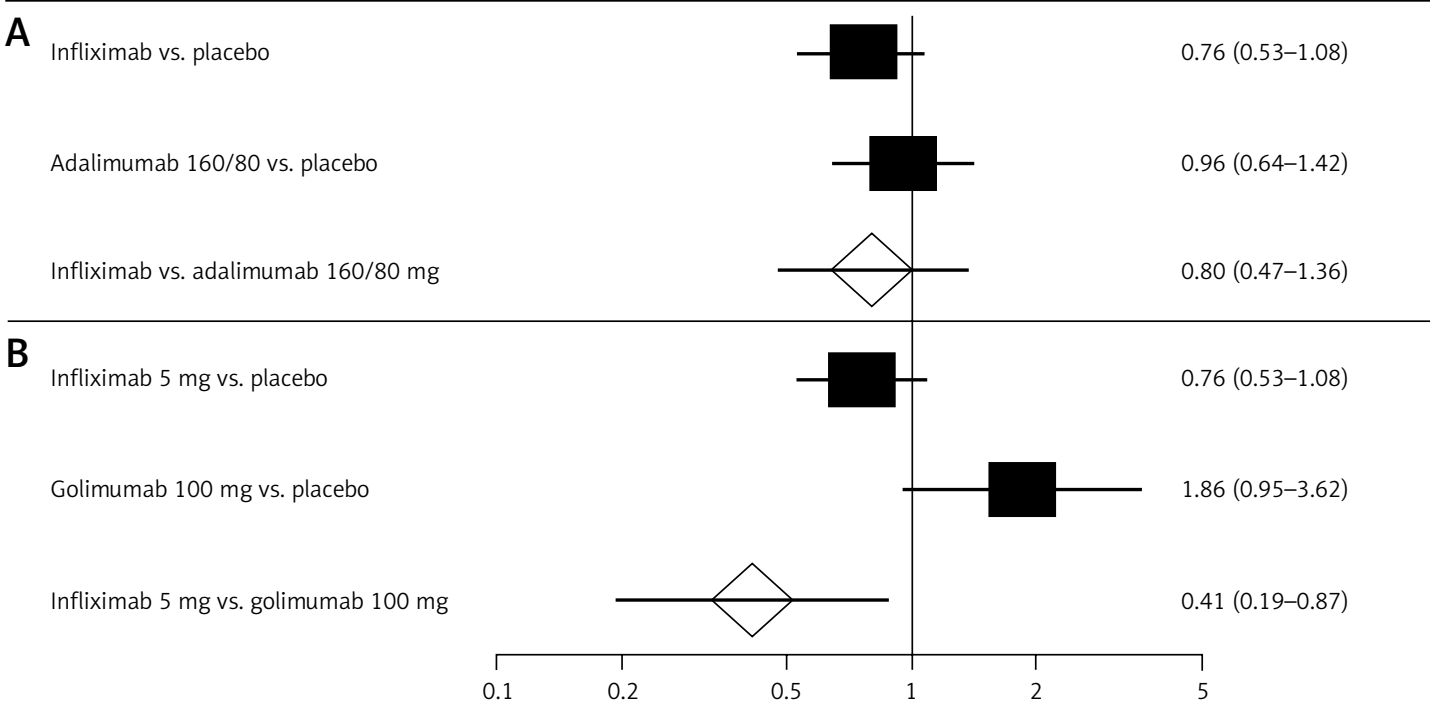

Figure 4. Forest plot of direct estimates for: A - infliximab (5 mg) vs. placebo and adalimumab (160/80 mg) vs. placebo, and indirect comparison between treatments in the case of serious adverse events after 52-54 weeks of drug administration; B - infliximab (5 mg) vs. placebo and golimumab (100 mg) vs. placebo, and indirect comparison between treatments in the case of serious adverse events after 52-54 weeks of drug administration

Table V. Results of an adjusted indirect comparison between t he safety profile of infliximab and adalimumab or infliximab and golimumab

\begin{tabular}{|c|c|c|}
\hline \multirow[t]{2}{*}{ Variable } & \multicolumn{2}{|c|}{ 52-54 weeks } \\
\hline & $\begin{array}{l}\text { Adverse events } \\
(\operatorname{RR}(95 \% \mathrm{Cl}))\end{array}$ & $\begin{array}{c}\text { Serious adverse events } \\
\text { (RR }(95 \% \mathrm{Cl}))\end{array}$ \\
\hline \multicolumn{3}{|c|}{ Infliximab 5 mg vs. adalimumab 160/80 mg } \\
\hline $\begin{array}{l}\text { Infliximab [37], [38] vs. } \\
\text { adalimumab [33], [39-41] }\end{array}$ & $\begin{array}{c}1.04(0.94-1.16) \\
p>0.05\end{array}$ & $\begin{array}{c}0.80(0.47-1.36) \\
p>0.05\end{array}$ \\
\hline \multicolumn{3}{|c|}{ Infliximab 5 mg vs. adalimumab 80/40 mg } \\
\hline $\begin{array}{l}\text { Infliximab [37], [38] vs. } \\
\text { adalimumab [32] }\end{array}$ & $\begin{array}{c}0.96(0.79-1.16) \\
p>0.05\end{array}$ & $\begin{array}{c}0.59(0.27-1.31) \\
p>0.05\end{array}$ \\
\hline \multicolumn{3}{|c|}{ Infliximab 5 mg vs. golimumab 100 mg } \\
\hline $\begin{array}{l}\text { Infliximab [37], [38] vs. } \\
\text { golimumab [43] }\end{array}$ & $\begin{array}{c}0.96(0.81-1.14) \\
p>0.05\end{array}$ & $\begin{array}{c}0.41(0.19-0.87) \\
p=0.0205\end{array}$ \\
\hline \multicolumn{3}{|c|}{ Infliximab 5 mg vs. golimumab 50 mg } \\
\hline $\begin{array}{l}\text { Infliximab [37], [38] vs. } \\
\text { golimumab [43] }\end{array}$ & $\begin{array}{c}0.97(0.82-1.15) \\
p>0.05\end{array}$ & $\begin{array}{c}0.69(0.30-1.59) \\
p>0.05\end{array}$ \\
\hline
\end{tabular}

and harm of adalimumab, golimumab, infliximab, and vedolizumab in adult patients with moderately-to-severely active UC who were naive to biologics was performed by Danese et al. [53]. They obtained results similar to ours; in particular, they found that infliximab was more effective in inducing a clinical response and mucosal healing than adalimumab in the induction phase. For inducing a clinical response, the odds ratio was $2.36(95 \% \mathrm{Cl}$ : $1.22-4.63)$, and for mucosal healing, it was 2.02 (95\% Cl: 1.13-3.59).

Calculations in the indirect comparison were based on published study results instead of individual patient data, which may generate bias. Despite the fact that populations from the in- cluded studies were quite homogeneous in their characteristics - mean age in each group, women-to-men ratio, degree of UC (Mayo score) and inflammation (C-reactive protein levels), and definitions of the inclusion criteria and selected study endpoints were similar, there were important differences that might have affected the results of the indirect comparison between infliximab and adalimumab treatments. As shown in Table II, first, patients were allowed to use concomitant medications in clinical trials, and only in the infliximab-treated population did they receive high levels of corticosteroids ( $\geq 20 \mathrm{mg} /$ day), which might have affected the results for infliximab treatment, and it may explain why infliximab seems to have 
better efficacy than adalimumab in the induction phase of drug administration. Second, the mean duration of disease from onset was longer in patients treated with adalimumab, and this might also have interfered with our results.

The strengths of this systematic review include strict methodology based on the methods and recommendations from the PRISMA Statement [23] and Cochrane Handbook [24], concerning a clear search strategy and predefined inclusion criteria for studies to be included in a systematic review and meta-analysis. Furthermore, only RCTs were taken into consideration. Data extraction and calculations were performed independently by two authors. The analysis depending on the heterogeneity of data and an appropriate statistical model was applied (fixed- or random-effects) [3]. This systematic review and indirect comparison also included data for the most important clinical outcomes in terms of the efficacy and safety of the biologic therapy and individual biologics in patients with moderately-to-severely active UC. Finally, it included a new biologic, golimumab, recently approved by the FDA [16] and the EMA [17] for this particular indication.

The compared datasets included data only from randomized, double-blind, placebo-controlled and parallel RCT phase II/III studies. Results from nonrandomized or uncontrolled open-label studies were not incorporated into the dataset [1]. The population of interest included patients with moderately-to-severely active UC treated with anti-TNF- $\alpha$ agents: infliximab, adalimumab, and golimumab. A diagnosis of UC was confirmed by biopsy and was defined as a Mayo score ranging from 6 to 12 points with an endoscopy subscore of at least 2. Eligible populations of patients were adults with a biopsy-established diagnosis of moderately-to-severely active UC despite concurrent treatment with stable doses of oral corticosteroids or immunomodulators (such as azathioprine or 6-mercaptopurine), or both. Patients concurrently treated with oral corticosteroids or immunomodulators were receiving a stable dose prior to baseline. Concurrent therapy was not required for patients who failed to respond to or could not tolerate previous corticosteroid or immunomodulator treatment, as assessed by the investigator. Patients who received infliximab, adalimumab, golimumab, or any other anti-TNF therapy in the past were not eligible. The key exclusion criteria included a history of colectomy or planned bowel surgery, ongoing infections (in particular confirmed tuberculosis), or the use of any investigational agent within 30 days or five half-lives prior to baseline.

We excluded a clinical trial by Jarnerot et al. [54], which was one of the search results for infliximab studies. The reason was that population characteristics when the treatment was used only in patients with a positive fulminant colitis index or in those demonstrating a severe or moderately severe attack of UC not responding to corticosteroid treatment were different from those analyzed in our meta-analysis. Patients in this population [52] had strong inflammation: the median C-reactive protein value was $65 \mathrm{mg} / \mathrm{l}$ in the infliximab group and $44 \mathrm{mg} / \mathrm{l}$ in the placebo group, in comparison to $8 \mathrm{mg} / \mathrm{l}$ and $7 \mathrm{mg} / \mathrm{l}$ for the infliximab and placebo groups, respectively, in the ACT- 1 and ACT-2 studies [37, 38] as well as in comparison with patients in the included studies on adalimumab or golimumab.

Despite the above limitations, this systematic review and indirect comparison enabled us to compare the effectiveness of infliximab vs. adalimumab and infliximab vs. golimumab in patients with moderately-to-severely active UC. The growing number of patients with UC imposes the need to develop new agents to effectively induce and maintain remission, improve quality of life, and prevent colectomy in this patient group.

\section{Conflict of interest}

The authors declare no conflict of interest.

\section{References}

1. Danese S, Fiocchi C. Ulcerative colitis. N Engl J Med 2011; 365: 1713-25.

2. Abraham C, Cho JH. Inflammatory bowel disease. N Engl J Med 2009; 361: 2066-78.

3. Kawalec P, Mikrut A, topuch S. A systematic review of the effectiveness of biological therapy for active moderate to severe ulcerative colitis: biological therapy for ulcerative colitis. J Gastroenterol Hepatol 2014; 29: 1159-70.

4. Molodecky NA, Soon IS, Rabi DM, et al. Increasing incidence and prevalence of the inflammatory bowel diseases with time, based on systematic review. Gastroenterology 2012; 142: 46-54.

5. Ordás I, Eckmann L, Talamini M, Baumgart DC, Sandborn WJ. Ulcerative colitis. Lancet 2012; 380: 1606-19.

6. Danese S, Sans M, Fiocchi C. Inflammatory bowel disease: the role of environmental factors. Autoimmun Rev 2004; 3: 394-400.

7. Molodecky NA, Gilaad GK. Environmental risk factors for inflammatory bowel disease. Gastroenterol Hepatol 2010; 6: 339-46.

8. Wang YF, Ou-Yang Q, Xia B, et al. Multicenter case-control study of risk factors for ulcerative colitis in China. World J Gastroenterol 2013; 19: 1827-33.

9. Ananthakrishnan AN. Environmental risk factors for inflammatory bowel disease. Gastroenterol Hepatol 2013; 9: 367-74

10. Baumgart DC, Carding SR. Inflammatory bowel disease: cause and immunobiology. Lancet 2007; 369: 1627-40.

11. Prideaux L, Kamm MA, De Cruz PP, Chan FKL, Ng SC. Inflammatory bowel disease in Asia: a systematic review. J Gastroenterol Heaptol 2012; 27: 1266-80. 
12. Sicilia B, Arribas F, Nerín J, López Miguel C, Vincente R, Gomollón. Risk factors for ulcerative colitis: a population-based, case-control study in Spain. J Crohns Colitis 2008; 2: 158-61.

13. Travis SPL, Stange EF, Lémann $M$, et al. European evidence-based Consensus on the management of ulcerative colitis: current management. J Crohns Colitis 2008; 2: 24-62.

14. Mowat C, Cole A, Windsor A, et al. Guidelines for the management of inflammatory bowel disease in adults. Gut 2010; 60: 571-607.

15. Kornbluth A, Sachar DB, The Practice Parameters Committee of the American College of Gastroeneterology. Ulcerative colitis practice guidelines in adults: American College of Gastroeneterology, Practice Parameters Committee. Am J Gastroenterol 2010; 105: 501-23.

16. US Food and Drug Administration. 2013. Available from URL: http://www.fda.gov/.

17. European Medicine Agency. 2013. Available from URL: http://www.ema.europa.eu/.

18. Scallon BJ, Arevalo Moore M, Trinh H, Knight DM, Ghrayeb J. Chimeric anti-TNF-alpha monoclonal anti-body CA2 binds recombinant transmembrane TNF-alpha and activates immune effector functions. Cytokine 1995; 7: 251-9.

19. Tracey D, Klareskog L, Sasso EH, Salfeld JG, Tak PP. Tumor necrosis factor antagonist mechanisms of action: a comprehensive review. Pharmacol Ther 2008; 117: 244-79.

20. Chan AC, Carter PJ. Therapeutic antibodies for autoimmunity and inflammation. Nat Rev 2010; 10: 301-16.

21. Bucher HC, Guyatt GH, Griffith LE, Walter SD. The results of direct and indirect treatment comparisons in meta-analysis of randomized controlled trials. J Clin Epidemiol 1997; 50: 683-91.

22. Kawalec P, Mikrut A, Wiśniewska N, Pilc A. Tumor necrosis factor-alpha antibodies (infliximab, adalimumab and certolizumab) in Crohn's disease: systematic review and meta-analysis. Arch Med Sci 2013; 9: 765-79.

23. Moher D, Liberati A, Tetzlaff J, Altman DG, PRISMA Group. Preferred Reporting Items for Systematic Reviews and Meta-Analyses: The PRISMA Statement. PLoS Med 2009; 6: e1000097.

24. Higgins JP, Green S. Cochrane handbook for systematic reviews of interventions. Cochrane Collaboration and John Wiley 2008.

25. Gornet JM, Couve S, Hassani Z. Infliximab for refractory ulcerative colitis or indeterminate colitis: an open-label multicentre study. Aliment Pharmacol Ther 2003; 18: 175-81.

26. Reinisch W, Sandborn WJ, Rutgeerts P, et al. Long-term infliximab maintenance therapy for ulcerative colitis: the ACT-1 and -2 extension studies. Inflamm Bowel Dis 2012; 18: 201-11.

27. Gustavsson A, Järnerot G, Hertervig E, et al. Clinical trial: colectomy after rescue therapy in ulcerative colitis - 3-year follow-up of the Swedish-Danish controlled infliximab study. Aliment Pharmacol Ther 2010; 32: 984-9.

28. Feagan BG, Reinisch W, Rutgeerts P, et al. The effects of infliximab therapy on health-related quality of life in ulcerative colitis patients. Am J Gastroenterol 2007; 102: 794-802.

29. Järnerot G, Hertervig E, Friis-Liby I, et al. Infliximab as rescue therapy in severe to moderately severe ulcerative colitis: a randomized, placebo-controlled study. Gastroenterology 2005; 128: 1805-11.
30. Probert CS, Hearing SD, Schreiber S, et al. Infliximab in moderately severe glucocorticoid resistant ulcerative colitis: a randomised controlled trial. Gut 2003; 52: 998-1002.

31. Reinisch W, Sandborn WJ, Hommes DW, et al. Adalimumab for induction of clinical remission in moderately to severely active ulcerative colitis: results of a randomised controlled trial. Gut 2011; 60: 780-7.

32. Suzuki Y, Motoya S, Hanai H, et al. Efficacy and safety of adalimumab in Japanese patients with moderately to severely active ulcerative colitis. J Gastroenterol 2014; 49: 283-94.

33. Jadad AR, Moore RA, Carroll D, et al. Assessing the quality of reports of randomized clinical trials: is blinding necessary? Control Clin Trials 1996; 17: 1-12.

34. Summary of Product Characteristics. Infliximab. Available from URL: http://www.ema.europa.eu/docs/en GB/document_library/EPAR___Product_Information/ human/000240/WC500050888.pdf

35. Summary of Product Characteristics. Adalimumab. Available from URL: http://www.ema.europa.eu/docs/ en_GB/document_library/EPAR_-_Product_Information/human/000481/WC500050870.pdf

36. Summary of Product Characteristics. Golimumab. Available from URL: http://www.ema.europa.eu/docs/en GB/document_library/EPAR_-_Product_Information/ human/000992/WC500052368.pdf

37. Rutgeerts P, Sandborn WJ, Feagan BG, et al. Infliximab for induction and maintenance therapy for ulcerative colitis. N Engl J Med 2005; 353: 2462-76.

38. Sandborn WJ, Rutgeerts P, Feagan BG, et al. Colectomy rate comparison after treatment of ulcerative colitis with placebo or infliximab. Gastroenterology 2009; 137: 1250-60.

39. Sandborn WJ, van Assche G, Reinisch W, et al. Adalimumab induces and maintains clinical remission in patients with moderate-to-severe ulcerative colitis. Gastroenterology 2012; 142: 257-65.

40. Sandborn WJ, Colombel JF, D'Haens G, et al. One-year maintenance outcomes among patients with moderately-to-severely active ulcerative colitis who responded to induction therapy with adalimumab: subgroup analyses from ULTRA 2. Aliment Pharmacol Therap 2013; 37: 204-13.

41. Feagan BG, Sandborn WJ, Lazar A, et al. Adalimumab therapy is associated with reduced risk of hospitalization in patients with ulcerative colitis. Gastroenterology 2014; 146: 110-8.

42. Sandborn WJ, Feagan BG, Marano C, et al. Subcutaneous golimumab induces clinical response and remission in patients with moderate-to-severe ulcerative colitis. Gastroenterology 2014; 146: 85-95.

43. Sandborn WJ, Feagan BG, Marano C, et al. Subcutaneous golimumab maintains clinical response in patients with moderate-to-severe ulcerative colitis. Gastroenterology 2014; 146: 96-109.

44. A study of adalimumab in Japanese subjects with moderately to severely active ulcerative colitis. NCT00853099. Available from URL: https://clinicaltrials.gov/ct2/show/ results/NCT00853099?term $=$ NCT00853099\&rank $=1 \&$ sect=Xh430156\#outcome11.

45. Ordás I, Eckmann L, Talamini M, Baumgart DC, Sandborn WJ. Ulcerative colitis. Lancet 2012; 380: 1606-19.

46. Assadsangabi A, Lobo AJ. Diagnosing and managing inflammatory bowel disease. Practitioner 2013; 257: 13-8, 2.

47. Warner BW. Short- and long-term complications of colectomy. J Ped Gastroenterol Nutr 2009; 48 (Suppl. 2) $72-4$. 
48. Tulchinsky H, Hawley PR, Nicholls J. Long-term failure after restorative proctocolectomy for ulcerative colitis. Ann Surg 2003; 238: 229-34.

49. Waljee A, Waljee J, Morris AM, Higgins PDR. Three-fold increased risk of infertility: a meta-analysis of infertility after ileal pouch anal anastomosis in ulcerative colitis. Gut 2006; 55: 1575-80.

50. Lawson MM, Thomas AG, Akobeng AK. Tumour necrosis factor alpha blocking agents for induction of remission in ulcerative colitis. Cochrane Database Syst Rev 2009; 3: CD005112.

51. Ford AC, Sandborn WJ, Khan KJ, Hanauer SB, Talley NJ, Moayyedi P. Efficacy of biological therapies in inflammatory bowel disease: systematic review and metaanalysis. Am J Gastroenterol 2011; 106: 644-59.

52. Hawkins N, Wu O. Meta-analysis and systematic literature review. ISPOR $14^{\text {th }}$ Annual European Congress. 2011.

53. Danese S, Fiorino G, Peyrin-Biroulet L, et al. Biological agents for moderately to severely active ulcerative colitis: a systematic review and network meta-analysis. Ann Intern Med 2014; 160: 704-11.

54. Jarnerot G, Hertervig E, Friis-Liby I, Blomquist L, Karlen $\mathrm{P}$, Granno $\mathrm{C}$ et al. Infliximab as rescue therapy in severe to moderately severe ulcerative colitis: a randomized, placebo-controlled study. Gastroenterology 2005; 128: $1805-11$. 